\title{
Application of a neuroscience research model to study neuroprotection in children with congenital heart disease
}

Nobuyuki Ishibashi, MD, and Richard A. Jonas, MD

\author{
From the Division of Cardiovascular Surgery and Center for Neuroscience Research, Children's National Medical \\ Center, Washington, DC \\ Disclosures: Authors have nothing to disclose with regard to commercial support. \\ Received for publication June 26, 2018; accepted for publication June 27, 2018; available ahead of print Aug 7, \\ 2018. \\ Address for reprints: Richard A. Jonas, MD, Division of Cardiovascular Surgery, Children's National Medical \\ Center, 111 Michigan Ave, NW, Washington, DC 20010-2970 (E-mail: lyoung@ cnmc.org). \\ J Thorac Cardiovasc Surg 2018;156:2281-2 \\ $0022-5223 / \$ 36.00$ \\ Copyright (c) 2018 by The American Association for Thoracic Surgery \\ https://doi.org/10.1016/j.jtcvs.2018.06.067
}

Over the past 10 to 20 years, it has become clear that neurologic deficits associated with congenital heart disease (CHD) are not simply a consequence of surgery and exposure to cardiopulmonary bypass. The causes are in fact cumulative and multifactorial. ${ }^{1}$ They include prenatal events such as genetic alterations such as ubiquitous copy number variants or disturbances of fetal cerebral blood flow. ${ }^{2,3}$ Brain development is often delayed in a fetus with CHD resulting in an immature brain even in a newborn infant born at full term. And an immature brain appears to be exquisitely susceptible to the inflammation (eg, systemic inflammatory response syndrome) and hypoxia/ischemia that can be a consequence of surgery. ${ }^{4}$ It is possible that current management strategies of cardiopulmonary bypass (CPB) and deep hypothermic circulatory arrest (DHCA) that are optimal for protection in a normally developing brain are damaging to a brain with immaturity and preoperative injury.

Huang and colleagues ${ }^{5}$ from Shanghai Children's Medical Center describe an innovative study using temperaturecontrolled neonatal rat brain slices exposed to oxygen glucose deprivation to simulate DHCA. The authors found that injury to preoligodendrocytes could be reduced either by deep hypothermia or application of minocycline. Injury to preoligodendrocytes is clinically relevant to cardiac surgeons because it can result in white matter injury that has been a signature insult observed in babies with CHD before surgery with exacerbation after surgery. White matter injury can become manifest as motor deficits, such as incoordination, as well as behavior problems such as attention deficit hyperactivity disorder, similar to the problems seen in ultrapremature populations.

The work reported by Huang and colleagues ${ }^{5}$ builds on a previous study from our laboratory using a rodent brain slice model that also documented the protective effect of deep hypothermia. ${ }^{6}$ In addition, it builds on work that demonstrated using an in vivo rodent model that minocycline could reduce hypoxic ischemic injury in developing

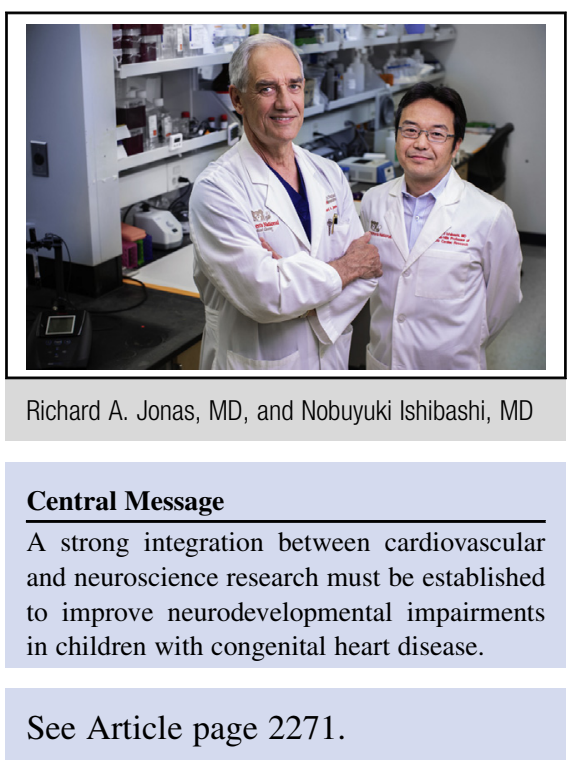

oligodendrocytes. ${ }^{7}$ The authors of the current report hypothesize that activation of microglia, the macrophages of the central nervous system, plays a pivotal role in oxygen glucose deprivation-induced preoligodendrocyte injury and that this microglial activation is inhibited both by minocycline and deep hypothermia. In the previous report, ${ }^{7}$ a direct effect of microglia cells on preoligodendrocyte injury was not confirmed; however, the current report suggests more directly an important association between microglia activation and preoligodendrocyte damage in white matter injury after CPB. The current report did not test the efficacy of minocycline application in immature brains.

A previous report has described prolonged microglia activation after full-flow $\mathrm{CPB}$ and circulatory arrest in a piglet model. ${ }^{8}$ The inference from that study and the current report is that reducing microglia activation may be an intervention that will limit further damage in an immature brain. However, further studies are required to refine this and other methods of adjunctive neuroprotection during cardiac surgery in these particularly vulnerable newborn infants.

The brain slice model used in the current report is certainly different from CPB/DHCA. However, this model is widely used in the neuroscience community and is accepted as a useful simulation of global cerebral hypoxia and ischemia. Going forward, this model will allow the study of the effects of pharmacologic therapy on immature brains that have developed under hypoxic conditions or 
genetically manipulated brains. ${ }^{9}$ Integration between cardiovascular and neuroscience research will be helpful in determining the complex cellular mechanisms underlying the brain injury seen in CHD populations. Ultimately it is to be hoped that collaboration between neuroscience and cardiac surgery research will lead to improved neurodevelopmental outcomes and reduce behavior problems that are commonly seen in teenaged and young adult populations living with repaired CHD.

\section{References}

1. Morton PD, Ishibashi N, Jonas RA. Neurodevelopmental abnormalities and congenital heart disease: insights into altered brain maturation. Circ Res. 2017; 120:960-77.

2. Miller SP, McQuillen PS, Hamrick S, Xu D, Glidden DV, Charlton N, et al. Abnormal brain development in newborns with congenital heart disease. $N$ Engl J Med. 2007:357:1928-38.
3. Homsy J, Zaidi S, Shen Y, Ware JS, Samocha KE, Karczewski KJ, et al. De novo mutations in congenital heart disease with neurodevelopmental and other congenital anomalies. Science. 2015;350:1262-6.

4. Beca J, Gunn JK, Coleman L, Hope A, Reed PW, Hunt RW, et al. New white matter brain injury after infant heart surgery is associated with diagnostic group and the use of circulatory arrest. Circulation. 2013;127:971-9.

5. Huang J, Liu G, Shi B, Shi G, He X, Lu Z, et al. Inhibition of microglial activation by minocycline reduced preoligodendrocyte injury in a neonatal rat brain slice model. J Thorac Cardiovasc Surg. 2018;156:2271-80.

6. Agematsu K, Korotcova L, Scafidi J, Gallo V, Jonas RA, Ishibashi N. Effects of preoperative hypoxia on white matter injury associated with cardiopulmonary bypass in a rodent hypoxic and brain slice model. Pediatr Res. 2014;75:618-25.

7. Cai Z, Lin S, Fan LW, Pang Y, Rhodes PG. Minocycline alleviates hypoxicischemic injury to developing oligodendrocytes in the neonatal rat brain. Neuroscience. 2006;137:425-35.

8. Korotcova L, Kumar S, Agematsu K, Morton PD, Jonas RA, Ishibashi N. Prolonged white matter inflammation after cardiopulmonary bypass and circulatory arrest in a juvenile porcine model. Ann Thorac Surg. 2015;100:1030-7.

9. Agematsu K, Korotcova L, Morton PD, Gallo V, Jonas RA, Ishibashi N. Hypoxia diminishes the protective function of white-matter astrocytes in the developing brain. J Thorac Cardiovasc Surg. 2016;151:265-72. e1-3. 